\title{
Suplicantes y ciudadanos con derechos: los padres de familia en secundarias federales del Distrito Federal (1932-1939)
}

\section{Supplicants and Citizens with Rights: Parents in the Federal Districts Federal High Schools (1932-1939)}

\author{
Aymara Flores Soriano \\ Escuela Nacional de Antropología e Historia \\ afloressoriano@gmail.com
}

\begin{abstract}
Resumen
El artículo analiza las formas y argumentos de los padres de familia del Distrito Federal para ejercer el derecho a la educación secundaria de sus hijos en el México posrevolucionario. Los datos empíricos fueron recuperados de la correspondencia de los padres a la autoridad educativa, expedientes personales de los alumnos, notas periodísticas y editoriales publicadas en la prensa nacional, así como discursos oficiales contenidos en las Memorias de la Secretaría de Educación Pública. Desde la historia social, se interpretan las interacciones entre los padres de familia y los agentes del Estado como prácticas de ciudadanía enmarcadas en un continuum que iba desde la súplica hasta la exigencia del derecho social a la educación, posiciones a partir de las cuales se establecieron negociaciones con un Estado que, en algunos casos como la falta de recursos monetarios o la insuficiencia de infraestructura, mostró cierta debilidad en sus instituciones.
\end{abstract}

Palabras clave: Secundaria; ciudadanía; padres de familia; Estado posrevolucionario; historia de la educación.

\begin{abstract}
This article analyzes the methods and arguments used by parents in Mexico City to fulfil their children's right to a high school education in post-revolutionary Mexico. Empirical data was collected from the correspondence between parents and the educational authorities, pupils' personal files, newspaper articles and editorials published in the national press, and official speeches transcribed in the Secretariat of Public Education's Reports. In terms of social history, the exchanges between parents and state officials are interpreted as citizenship practices framed in a continuum that ranges from entreaties to demands for the social right to education. From these positions, negotiations were conducted with the state which, in some cases such as the lack of monetary resources or infrastructure, revealed a certain weakness in its institutions.
\end{abstract}

Key words: high school; citizenship; parents; post-revolutionary state; history of education.

Fecha de recepción: 28 de octubre de 2013 Fecha de aceptación: 9 de junio de 2014

Secuencia, ISSN 0186-0348, núm. 94 | enero-abril de 2016 | pp. 181-209

\section{(ㅇ)(1) $\$$}




\title{
Suplicantes y ciudadanos con derechos: los padres de familia en secundarias federales del Distrito Federal (1932-1939)*
}

\author{
Aymara Flores Soriano
}

$\mathrm{E}^{\mathrm{n}}$ n 1934 el Departamento de Enseñanza Secundaria en el Distrito Federal (DESDF), dependiente de la Secretaría de Educación Pública (SEP), reportó que de 12600 alumnos que terminaban el sexto año de primaria, 7000 se inscribían a primero de secundaria en las escuelas federales; es decir, 56\% de quienes lograban concluir los estudios primarios continuaban en el siguiente nivel educativo. ${ }^{1}$ Si tomamos en cuenta la corta vida de la secundaria como nivel independiente de los estudios primarios y los preparatorianos, ya que no alcanzaba ni los diez años de creación, la cifra resulta reveladora en términos de recepción y demanda por parte de la población del Distrito Federal. ${ }^{2}$

En el contexto de la construcción del Estado posrevolucionario mexicano, la puesta en marcha de las escuelas secundarias federales en la capital del país abrió diferentes espacios de participación para los padres y madres de familia que vieron en la educación oficial una opción para los estudios posprimarios de sus hijos. En este artículo analizo dicha participación a través de la interacción de los padres con los agentes del Estado. Con este trabajo pretendo aportar a la reciente historiografía que se propone documentar las

* Artículo derivado de la tesis para obtener el grado de maestra en Ciencias con especialidad en Investigaciones Educativas del CinvestaV.

${ }^{1}$ Cuadros comparativos de asistencia de alumnos y presupuestos para la enseñanza secundaria (1935). Fondo Departamento de Enseñanza Secundaria en el Distrito Federal. Escuelas Secundarias Federales. 1931-1944. Caja 2, exp. 1, fs. 1 y 2. Archivo Histórico de la Secretaría de Educación Pública (AHSEP), México.

${ }^{2}$ El 29 de agosto de 1925, bajo el mandato de Plutarco Elías Calles, se estableció en el decreto presidencial 1848 la autorización a la SEP para crear escuelas secundarias. La Dirección de Educación Secundaria sería la oficina federal que tendría la jurisdicción técnica y administrativa de dicho nivel educativo, según el decreto presidencial 1850, el cual también ordenaba que a partir de enero de 1926 la Universidad Nacional debía separar los cursos secundarios que hasta la fecha se impartían en la Escuela Nacional Preparatoria (ENP) para que quedaran bajo la dirección del nuevo departamento de la SEP (Mejía, 1976, p. 130).

\section{()ㅜ(1) $\$$}


prácticas de los ciudadanos en sus contextos socioculturales, más allá de medir el éxito o el fracaso de su estatus de ciudadanía (López y Acevedo, 2012). ${ }^{3}$

A su vez, esta investigación se inscribe en la perspectiva de la historia social de la educación, la cual entiende lo educativo como un proceso complejo que abarca instituciones, actores, y prácticas sociales y discursivas, analizados en contextos socioculturales que condensan la relación de lo local con lo regional y/o lo nacional. La historia social de la educación en México, principalmente para el periodo posrevolucionario, ha puesto atención en los procesos de negociación, diálogo, apropiación, conflicto y resistencia que diversos grupos de la sociedad han entablado a partir de los proyectos educativos emanados desde el Estado (Civera, 1997; Rockwell, 2007; Vaughan y Quintanilla, 1997; Vaughan, 2000). Si bien dicha historiografía ha estado más centrada en contextos rurales, resulta útil para analizar los mismos procesos en los espacios urbanos. ${ }^{4}$

En algunos estudios regionales, la participación de los padres y madres de familia ha sido situada por los diferentes autores dentro de categorías más amplias: comunidad, vecinos y campesinos (Alfonseca 2005; Civera, 1997; Rockwell, 2007; Vaughan, 2000). En contextos urbanos, como los casos aquí analizados, ¿cómo caracterizar a los padres y madres de familia? Propongo que la lente de análisis de las prácticas ciudadanas puede ser útil para comprender la participación de estos actores en el Distrito Federal durante el periodo posrevolucionario. Al hablar de padres de familia, me refiero a un colectivo heterogéneo cuya diversidad estuvo marcada por categorías de género, clase social y nivel educativo. Estas adscripciones socioculturales distinguieron las formas de interacción entre los padres de familia y los diferentes agentes del Estado de acuerdo con las preocupaciones de los primeros en relación con la educación secundaria de sus hijos.

${ }^{3}$ Me adscribo a la postura de López y Acevedo (2012, p. 22), quienes proponen un análisis de la ciudadanía que vaya más allá de su prescripción normativa y ponga atención en las prácticas que los ciudadanos realizan en la interacción social. A su vez, Lomnitz (2000) indica que para tener una visión comprehensiva de la ciudadanía, es necesaria "una interpretación de la relación entre las definiciones legales e institucionales de ciudadanía y su elaboración cultural en la interacción social" (p. 132). Un punto a aclarar es que para esta época las mujeres no contaban con el derecho político de voto, sin embargo, dicha restricción legal no impidió a las madres de familia el posicionarse frente a los funcionarios de la SEP, e incluso frente al presidente de la república, como merecedoras de educación para sus hijos.

${ }^{4}$ Cabe resaltar que también se han desarrollado estudios sobre la historia de la educación en la ciudad de México, como los compilados en el libro coordinado por Gonzalbo y Staples (2012), así como la obra de Schell (2003), entre otros.

\section{()(1) $\$$}


Las demandas y la defensa del derecho a la educación secundaria de los hijos aquí analizadas, entrelazaron discursos donde algunos padres, y sobre todo las madres, se presentaron como pobres merecedores o suplicantes, pero también manifestaron nuevas prácticas y retóricas donde el pacto entre los ciudadanos y el Estado posrevolucionario estuvo presente; por ejemplo, las referencias a la obligación del Estado a prestar servicios educativos a la población que apoyó a la revolución y los gobiernos emanados de ella fueron recurrentes en algunos discursos de los padres de familia. ${ }^{5}$

En los siguientes párrafos expondré cuáles fueron los temas y las formas en que se articulaban las interacciones entre los padres de familia de las secundarias federales 8 y 10 -ubicadas en San Pedro de los Pinos y Mixcoac, respectivamente $-{ }^{6} y$ las autoridades educativas. Mi objetivo es responder a la siguiente pregunta: ¿cómo demandaron los padres y las madres de familia el derecho a la educación secundaria de sus hijos durante el México posrevolucionario? Las respuestas a dicha interrogante, como se verá a continuación, estuvieron marcadas por la convergencia de los intereses de los actores involucrados: por un lado, la demanda social, es decir, el deseo de los padres para que sus hijos continuaran los estudios posprimarios, con lo cual podríamos establecer que en el Distrito Federal algunos sectores sociales empezaron a ver en la educación un medio de ascenso social. Y, por el otro, la necesidad del Estado posrevolucionario de legitimarse a través de la expansión de la escolarización, estableciendo las secundarias federales para ofrecer este nivel educativo a las clases trabajadoras, aun cuando no se contaba con la infraestructura necesaria para lograr dicho objetivo, por lo cual se abrió un espacio de negociación entre los padres y las madres de familia y el Estado.

La escuela secundaria moderna, entendida por los funcionarios educativos y por el ejecutivo como un nivel separado de los estudios preparatorios, controlada por la SEP y que atiende las necesidades pedagógicas y disciplinarias de los adolescentes, fue una creación que resultó de la discusión

${ }^{5}$ Rodríguez (2010), en su estudio sobre la revolución en la ciudad de México, establece que uno de los efectos de una revolución moderna, además de sus consecuencias materiales, es la reconfiguración de los imaginarios políticos de la población y las autoridades, incluyendo la "manera de ejercer la autoridad, de hacer política y de entender los derechos y obligaciones de los hombres" (p. 15).

${ }^{6}$ El acceso a los expedientes de los alumnos de la época, resguardado en las instalaciones de la Secundaria 10, y en el AHSEP, para la Secundaria número 8, me permitió articular las voces directas de los padres y madres de familia, a manera de ejemplo ante la imposibilidad de abarcar todas las secundarias de la ciudad. Cuando resulta relevante y tengo datos, hago referencia a otras secundarias del Distrito Federal o al conjunto de ellas.

\section{(ㅇ)(1) $\$$}


de su pertinencia durante el siglo xix y que se consolidó al término del movimiento revolucionario de inicios del xx (Arredondo, 2007 y 2008; Civera, 2008; Loyo, 2008; Santos, 2000). Desde el punto de vista oficial, la escuela secundaria sería un espacio educativo donde los adolescentes podrían adquirir los conocimientos que los prepararan para insertarse en el mercado laboral o para continuar con los estudios superiores. Con la separación de los estudios secundarios de la preparatoria, controlada por la Universidad Nacional, el gobierno callista buscó quitar el control de estos estudios a la Universidad, democratizar este nivel educativo y dar la oportunidad a los jóvenes provenientes de las clases trabajadoras de continuar estudiando una vez concluida la primaria y, de paso, tener el control de la certificación de dichos estudios.

\section{LA DEMANDA DE EDUCACIÓN SECUNDARIA Y SU GRATUIDAD: ENTRE EL POBRE MERECEDOR Y EL CIUDADANO}

El movimiento armado de 1910, el crecimiento de la administración pública y la industrialización de las décadas siguientes contribuyeron a la conformación de una incipiente clase media mexicana que tuvo sus orígenes durante el siglo xix (Arrom, 1988; Porter, 2002). La revolución ocasionó que, por un lado, algunos rancheros, ganaderos, grandes propietarios, comerciantes y funcionarios del régimen porfirista tuvieran un descenso social, pasando a formar parte de un sector medio rural y urbano; por otro lado, algunos pequeños propietarios, obreros calificados y profesionistas preparados para entrar al servicio gubernamental, ocuparon una posición predominante dentro de las clases medias mexicanas (Pérez, 1993, p. 42).

González (1974, p. 34) señala que durante el cardenismo uno de cada diez mexicanos era de clase media; por su parte, Iturriaga (1987, p. 144), basado en un estudio sociológico e histórico, determinó que para 1940 las clases medias en México conformaban $15.87 \%$ del total de la población. ${ }^{7}$ Durante

${ }^{7}$ Como lo han establecido varios autores, es difícil clasificar y definir a las clases medias, dada su gran capacidad de movilidad en periodos históricos cortos (Bertaccini, 2009; Contreras, 1978; González, 1974; Iturriaga, 1987; Loaeza, 1999; Mentz, 2003). Es por esto que cada autor, de acuerdo con sus intereses, ha retomado uno o varios criterios, ya sea la ocupación, el nivel educativo, el consumo o el ingreso familiar, entre otros, para definir y analizar los sectores intermedios en la escala social. Para analizar los casos aquí descritos, retomo la definición de Loaeza (1999), quien establece que, "lo que distingue a las clases medias mexi-

\section{(ㅇ)(1) $\$$}


los años treinta, el discurso y las políticas educativas voltearon la mirada a las urbes y sus habitantes, ahora identificados como proletariado. La SEP encontró en la capital del país un espacio educativo y social donde el concepto de clase social se erigiría como uno de los fundamentos para el desarrollo y diseño de las políticas educativas dirigidas a la población urbana (Britton, 1976, p. 87). En este contexto, la introducción de la educación secundaria en el Distrito Federal se convirtió en uno de los estandartes que permitiría al Estado materializar su idea de democratizar la educación y llevarla a las grandes masas, sobre todo a aquellos que antes de su creación se quedaban fuera de las filas de la Escuela Nacional Preparatoria.

A pesar del discurso de democratización de los estudios posprimarios, la misma SEP reconoció en 1932 que la mayor parte de los alumnos inscritos en sus secundarias no provenía de las familias populares; si así fuera, según la Secretaría de Educación, sería legítimo de un gobierno emanado de la revolución el decretar su obligatoriedad y gratuidad: "Pero de hecho no es el pueblo, la masa proletaria del país, la que llena nuestras escuelas secundarias. Esa está en los campos, en las fábricas, en la calle. El joven que puede permanecer en la escuela hasta los 16 o 18 años demuestra por ese solo hecho que pertenece a la clase media, única que recibe el beneficio" (Memoria, 1932, p. 332).

Si bien desde la creación de las escuelas secundarias federales ya se exigía a los padres de familia una cuota para que sus hijos ingresaran a estos centros escolares, en enero de 1932, previo al proceso de inscripción al nuevo ciclo escolar en las secundarias federales, el jefe del DESDF llamó a la participación de los padres de familia para que, a través de sus aportaciones monetarias -en forma de cuotas de inscripción y colegiaturas periódicasse pudieran sostener la renta del edificio, el mobiliario y los sueldos de los profesores requeridos. Una nota publicada en la primera plana del periódico Excélsior el 6 de enero de 1932 informó que, por órdenes del jefe del Departamento respectivo "se están cobrando diez pesos como colegiatura a cada alumno que va a secundaria [...]", debido a que la gratuidad sólo estaba ga-

canas es que desde el siglo xix reclaman una posición de liderazgo social con base en el derecho que se atribuyen a partir de sus características educativas y culturales. [...] Gozan de una larga tradición de toma de conciencia como grupo social diferenciado, la cual se funda en condiciones objetivas y en una aspiración común a afianzar su continuidad y permanencia como clase" (p. 42). Cabe resaltar que los funcionarios educativos de la época identificaron a los sectores medios con base en el salario percibido y su ocupación.

\section{(이)(1)}


rantizada constitucionalmente para el nivel primario y "de allí en adelante, los que deseen seguir una carrera deben pagar su educación”. ${ }^{8}$

Aunado a la incapacidad de la SEP para cubrir el mantenimiento y la creación de nuevos planteles de secundaria en el Distrito Federal, estaba el tema de la creciente demanda escolar. Según la misma nota del Excélsior, el problema de que no hubiera suficientes secundarias federales para atender a los jóvenes que deseaban cursar estos estudios, se debía a que, año con año, la labor educativa de las primarias hacía que egresaran de sus aulas una gran cantidad de alumnos que buscaban un lugar en las secundarias federales; por ello, a pesar de que la SEP pretendía que la escuela secundaria fuera democrática, debía implementar una selección de alumnos, la cual se apoyaría en el cobro de inscripción y colegiaturas. ${ }^{9}$ Otro de los filtros fue el establecimiento de un promedio mínimo de ingreso. El editorial de Excélsior del 7 de enero de 1932 hacía hincapié en que si los padres de familia cubrían las cuotas que la SEP requería, habría más escuelas secundarias para que los jóvenes del Distrito Federal asistieran a ellas. Además, recalcaba que las cuotas eran más bajas que las que se cobraban en los planteles privados, por lo cual, no se pondría en duda el carácter democrático de este nivel educativo. ${ }^{10}$

Dado que las condiciones del erario público no permitían el incremento en el presupuesto destinado a la enseñanza secundaria para el año de 1933, la SEP decidió incrementar las cuotas de colegiatura para los alumnos de 10 a 20 pesos anuales, a pagarse en dos exhibiciones: 10 pesos de inscripción y 10 de colegiatura a cubrir en el mes de julio (Memoria, 1933, p. 198). Esta tarifa se fijó al pedirle a los padres de familia, que según la SEP tenían los medios para cubrir la colegiatura - pues pertenecían a la clase media-, que contribuyeran con $10 \%$ del costo anual de la educación de sus hijos, que en promedio por alumno era de 233.76 pesos (Memoria, 1932, p. 332). A los padres que no pudieran costear dicho gasto, la Secretaría de Educación les otorgaría becas suficientes para que sus hijos accedieran a la enseñanza secundaria. Por lo tanto, según la SEP, el cobro de colegiaturas no afectaría los bolsillos de ningún mexicano, ya que "el pueblo verdadero, la masa pobre, no se perjudicaría porque para él la Secundaria sería absolutamente gratuita”. ${ }^{11}$

${ }^{8}$ En las secundarias de esta ciudad se pagará este año colegiatura. Excélsior, 4 de enero de 1932 , p. 1.

${ }^{9}$ Una vez más surge el problema por falta de escuelas secundarias. Excélsior, 6 de enero de 1932, primera plana.

${ }^{10}$ El problema de las Escuelas Secundarias. Excélsior, 7 de enero de 1932, p. 5.

11 El problema de las Escuelas Secundarias. Excélsior, 7 de enero de 1932, p. 5.

\section{(이요 $\$$}


En 1933 la SEP autorizó al Departamento de Enseñanza Secundaria conceder becas a $20 \%$ del total de los jóvenes inscritos en los planteles federales, "siempre que estos demostraran pobreza al mismo tiempo que inteligencia y dedicación al estudio" (Memoria, 1933, p. 198). De las secundarias federales instaladas en el Distrito Federal, la Secundaria número 5 nocturna para varones - a la cual asistían en su mayoría trabajadores-era la única que sobrepasaba el $20 \%$ de alumnos becados, por lo tanto, la SEP concluyó que la mayoría de las secundarias federales estaban pobladas por "hijos de la clase rica o de la clase media” que podían pagar sus estudios. Dicha conclusión se basaba también en la aseveración de que los niños "del pueblo" no lograban siquiera terminar la escuela primaria, pues debían desertar de ella al segundo o tercer año para dedicarse a trabajar, con lo cual "se va haciendo en nuestras escuelas y en nuestro país una selección con base puramente económica y fundamentalmente injusta" (Memoria, 1933, p. 199).

En 1935 la Secretaría de Educación llevó a cabo un censo entre los estudiantes de las secundarias federales de la capital para determinar su origen social; el parámetro de clasificación fue la ocupación y una estimación del sueldo percibido por el proveedor familiar. Aunque las clasificaciones de la SEP fueron un tanto vagas, pues no indicaban los criterios para establecer las diferencias en ocupaciones o sueldos de las familias, quedó implícito en los resultados un orden creciente según el monto del salario obtenido -de los más pobres a los más ricos-y de los propietarios de su fuerza de trabajo a los propietarios del capital: de "clase obrera muy pobre" a "capitalistas", pasando por la "clase obrera de mediano sueldo", "empleados públicos y particulares", "profesionales (médicos, ingenieros, abogados, maestros, etc.)" y "comerciantes" e "industriales". El censo demostró lo que la seP ya había argumentado: los hijos de los obreros no llenaban las aulas de las secundarias federales. Las cifras indicaron que $50 \%$ de los alumnos provenía de familias cuyos padres eran empleados - públicos o particulares-y profesionistas; $30 \%$ pertenecía a una clase más alta, hijos de "comerciantes", "industriales" y "capitalistas"; y sólo el $20 \%$ restante formaba parte de esa clase obrera a la que el gobierno posrevolucionario inicialmente decía beneficiar con la creación de la secundaria. ${ }^{12}$

${ }^{12}$ Clasificación de los alumnos de las Escuelas Secundarias Oficiales según la clase social a la que pertenecen de acuerdo con sus posibilidades económicas. 1935. Fondo Departamento de Enseñanza Secundaria en el Distrito Federal. 1932-1939. Escuela Secundaria Federal No. 8. Caja 2, leg. 1, f. 5. Ahser, México.

\section{(ㅇ)(1) $\$$}


Aun así, considero importante mencionar que después de obtener los resultados del censo escolar, el DESDF propuso la gratuidad de la secundaria, pero además, que se instaurara un sistema de becas para "los alumnos pobres y que reúnan condiciones distinguidas de capacidad, de buena conducta y aplicación". Estas becas serían, según el proyecto del Departamento, de tres tipos: 30 pesos anuales para la adquisición de equipos escolares; 5 pesos mensuales durante diez meses de año escolar para pasajes y compra de material escolar de consumo y una cantidad de entre 15 y 25 pesos mensuales para "los agraciados de notoria pobreza, que, por sus excepcionales condiciones de capacidad, laboriosidad y espíritu de servicio social, sean una positiva promesa para la dirección de los gremios del proletariado". ${ }^{13}$

No encontré ninguna fuente que anunciara la aceptación del proyecto de becas, y la gratuidad de la secundaria fue decretada hasta 1936. En cualquier caso, la propuesta muestra la idea de que algunas autoridades educativas tenían intenciones de beneficiar a las clases más desprotegidas a través de un discurso de caridad conservador, al estilo del utilizado por la beneficencia pública y por algunos sectores de la Iglesia católica en la década anterior: los pobres son "agraciados" más que ciudadanos ${ }^{14}$ pero unido a un objetivo más acorde al pensamiento revolucionario: formar líderes para el mejoramiento de las clases trabajadoras. El imaginario del pobre merecedor estuvo presente entre los funcionarios de la asistencia pública y la población en general desde finales del porfiriato, cuando se hizo una distinción entre aquellos que por su condición de pobreza merecían acceder a la beneficencia pública para convertirse en ciudadanos útiles -en un sentido económico y moral- para la sociedad mexicana (Lorenzo, 2011). ${ }^{15}$ De esta manera, los pobres honrados eran quienes, a pesar de sus condiciones sociales adversas, se mantenían alejados de los vicios y el crimen, por lo cual merecían la ayuda estatal para subsistir.

${ }^{13}$ Clasificación de los alumnos de las escuelas secundarias oficiales según la clase social a la que pertenecen de acuerdo con sus posibilidades económicas. 1935. Fondo Departamento de Enseñanza Secundaria en el Distrito Federal. 1932-1939. Escuela Secundaria Federal No. 8. Caja 2, leg. 1, f. 5. AHSEP, México.

${ }^{14}$ Desde la primera década del siglo xx, la llamada Acción Católica Social introdujo en México una serie de propuestas para llevar a las clases trabajadoras servicios médicos, educación y cooperativas (Schell, 2003, p. 10).

${ }_{15}$ Dicho imaginario puede ser rastreado en el discurso caritativo desde inicios del periodo colonial en México, pero es en el porfiriato cuando las autoridades encargadas de la beneficencia pública lo aplican para decidir quiénes merecían recibir los recursos asistenciales (Aguirre, García y Valero, 2002; Lorenzo, 2011).

\section{(ㅇ)(1) $\$$}


Como veremos a continuación, el imaginario del pobre merecedor apareció también en el campo educativo durante el cardenismo, específicamente en las solicitudes de exención del pago de cuotas para cursar la secundaria que los padres y las madres de familia enviaron al director de la escuela, al jefe del Departamento de Enseñanza Secundaria del Distrito Federal, al secretario de Educación Pública e incluso al presidente de la república.

En los años de 1934 y 1935, en la Secundaria 10 de Mixcoac, los padres y madres de familia de los sectores menos favorecidos expusieron a los funcionarios del DESDF la situación económica que les impedía cubrir las colegiaturas. La mayoría de los padres argumentaba tener más de cinco hijos, estar desempleados o ganar sueldos muy bajos que apenas les permitían sostener a su familia. ${ }^{16}$ Tal fue el caso del padre de Ciro Trinidad, alumno inscrito en el primer año, quien envió el 26 de febrero de 1934 una carta a la profesora Palma Guillén, jefa de Escuelas Secundarias del Distrito Federal, donde le solicitaba se le exceptuara del pago de colegiatura de su hijo debido a que el sueldo que percibía como empleado de una pescadería -1.50 pesos diarios- le era insuficiente para atender la alimentación y vestido de su esposa y siete hijos, por lo que le era imposible cubrir la colegiatura de Ciro. Además, la carta del padre incluía otra de referencia de un vecino de Mixcoac, Ernesto Luring, quien decía conocer a la familia Trinidad y aseguraba que "dentro de su pobreza y falta de recursos, padres e hijos son dignos de adelantar y mejorar de posición [social] y recibirán un bien de los que los ayuden, principalmente en lo referente a la Educación de sus muchachos" ${ }^{17}$ La madre del alumno Amador Castañeda Ruiz, por ejemplo, se apoyó de una carta de recomendación de la profesora Fructuosa Vera, quien aseguró a la profesora Palma Guillén que la señora Ruiz Castañeda era digna de la exención de dicho pago debido a que:

es persona honrada, trabaja en este establecimiento como Vigilante de Segunda con un sueldo ínfimo de $\$ 1.65$ diarios con el cual paga renta de casa y sostiene a 8 de familia, además como madre se interesa por la educación de sus pequeños hijos, teniendo un jovencito de 13 años de edad que asiste a la

${ }^{16}$ Expedientes de alumnos. Caja 1, exps. 32, 342 y 211. Archivo Histórico de la Secundaria Federal No. 10 "Leopoldo Ayala" (AHs10), México. Para los años de 1934 y 1935, el salario mínimo diario general para el Distrito Federal fue de 1.50 pesos, en 1936 aumentó a 2 pesos y en 1938 , a 2.50 pesos (INEGI, 2000, p. 171). Estos datos nos dan una perspectiva de lo oneroso que resultaba para las familias más pobres enviar a sus hijos a las escuelas secundarias federales.

${ }^{17}$ José Trinidad. Carta al jefe de Escuelas Secundarias del D. F. 26 de febrero de 1934. Expedientes de alumnos. Caja 1, exp. 17. AHs10, México.

\section{()(1) $\$$}


Secundaria número 3, no pudiendo ser admitido por no cubrir la cuota. De ser posible ruego a usted tenga la bondad de que se le exima de dicho pago por ser de familia bastante pobre. ${ }^{18}$

Para el señor Luring y la profesora Vera -en estos casos representantes de una autoridad moral que reconocían la "dignidad" de las familias de Ciro y Amador-, la educación secundaria era vista como un medio de movilidad social, pero debido a la pobreza que las familias argumentaban, necesitaban la "ayuda" del Estado para lograr dicho objetivo. En este sentido, durante los primeros años del cardenismo, entre la población del Distrito Federal, al igual que entre los funcionarios educativos, estuvo presente el imaginario del pobre merecedor: no bastaba ser ciudadano mexicano pobre para recibir beneficios estatales, se debía acreditar también un grado de "dignidad" que distinguía quién merecía ser beneficiario y quién no.

Los argumentos de Ernesto Luring y la profesora Fructuosa Vera aportan a la reflexión sobre las formas de dirigirse a la autoridad educativa y cómo se concebía el derecho a la educación de los hijos. Queda claro que la educación secundaria empieza a ser concebida como un medio de movilidad social para las clases trabajadoras urbanas, de ahí una explicación de su alta demanda en el Distrito Federal. Sin embargo, resulta revelador cómo quienes solicitaban la exención de cuotas se ubicaban y eran ubicados como pobres merecedores para los cuales se reservarían criterios basados en la honradez y el modo honesto de vivir para acceder a una política social. Con ello, vemos que la necesidad de mostrar honestidad no resultó ser exclusiva del discurso caritativo institucionalizado durante el porfiriato o del de la ciudadanía moderna del siglo xIX, ${ }^{19}$ sino que también permeó el del ciudadano mexicano posrevolucionario, a manera de continuum que trascendió el movimiento revolucionario del siglo $\mathrm{xx}$.

Cuando eran las madres de familia las que solicitaban la exención de los pagos, lo hacían a partir de disculparse por su condición económica y no solicitando el beneficio estatal de una beca. En varias cartas de madres de alumnos de la Secundaria número 10 ellas se disculpaban, suplicaban y apelaban al buen corazón de la autoridad educativa para que sus hijos pudie-

${ }^{18}$ Profa. Fructuosa. Carta al jefe de Escuelas Secundarias del D. F. 11 de enero de 1934. Expedientes de alumnos. Caja 1, exp. 32. AHs10, México.

${ }^{19}$ La ciudadanía moderna mexicana, bajo el modelo de lo establecido en la Constitución de Cádiz de 1812, reservaba los derechos ciudadanos a quienes cumplieran con las cualidades morales de la virtud y la dignidad (Guerra, 2002, p. 47).

\section{()(1) $\$$}


ran continuar sus estudios secundarios a pesar de no poder cubrir las cuotas exigidas. El 3 de abril de 1934, la señora Josefina Rueda de Romay, madre de Rafael Romay Rueda, envió una carta al director de la secundaria, Leopoldo Ayala, donde le exponía que

[...] desgraciadamente no voy a poder tener para ese día [el 10 de abril] el dinero [de la colegiatura correspondiente al primer semestre], pues como manifesté a Ud. mi esposo no tiene empleo y estos días de fiesta han sido difíciles para él por lo que estamos en situación verdaderamente difícil, por lo cual suplico a Ud. me diga si puede tenerme [dentro de la escuela] a mi hijo sin pagar $[\ldots] .^{20}$

A esta secundaria asistían también hijos de viudas, quienes, por no contar con un esposo que cubriera los gastos de la educación de sus hijos, rogaban al director de la secundaria que las ayudara para mantenerlos en la escuela. Este fue el caso de Joaquina viuda de Pineda, madre de Bernardino Pineda Vergara, quien solicitó la exención del pago debido a tres motivos: "Primero por ser viuda. Segundo por tener ocho pequeños hijos. Tercero por estar trabajando para sostenerme con mis mismos familiares. [Por lo que] esperaré de usted que con mis súplicas se cumpla alcanzar el anhelo de mi hijo en formarse una carrera, aunque humilde para poder conseguir un modo honesto para vivir." ${ }^{21}$

Para las madres de familia el solicitar la exención del pago de inscripción y de colegiatura para que sus hijos cursaran los estudios secundarios en las escuelas federales significó, tal vez, reconocer que el derecho a la educación no era para ellas, sino para sus hijos, que debían alcanzar el "modo honesto de vivir", requisito para acceder a la ciudadanía desde el siglo XIX. Además, no solicitaron las becas, suplicaron por ellas apelando a la compasión del director de la secundaria. A partir de estas formas de dirigirse a los funcionarios educativos, considero que entre las madres, mujeres que para la época no contaban con el derecho político del voto, se configuró una forma de cultura política donde la autoridad del Estado, representada en los funcionarios de la SEP, debía ser interpelada bajo argumentos más que políticos,

${ }^{20}$ Josefina Rueda de Romay. Carta a Leopoldo Ayala. 3 de abril de 1934. Expedientes de alumnos. Caja 1, exp. 61. AHs10, México. Las cursivas son mías.

${ }^{21}$ Joaquina Vergara vda. de Pineda. Carta a Leopoldo Ayala. 2 de mayo de 1934. Expedientes de alumnos. Caja 1, exp. 66. AHs10, México.

\section{(ㅇ)(1) $\$$}


de ahí la estrategia de apelar a su bondad y buena voluntad. Dicha estrategia ya había sido utilizada antes de la revolución, específicamente en cuanto a la beneficencia pública del porfiriato, cuando tal atención más que una obligación del Estado, era tratada como una responsabilidad moral (Lorenzo, 2011, pp. $42,194,197$ y 211-217).

Todas las solicitudes de los padres de familia de la Secundaria 10 que pedían no realizar los pagos de las cuotas, enviadas entre los años de 1934 y 1935, fueron atendidas por las autoridades correspondientes y se aprobó para ellos la exención del pago. Estos casos exhiben, como lo he mencionado, el interés que los padres de familia empobrecidos o de las clases menos favorecidas tenían en la educación de sus hijos, pues veían en ella el medio para mejorar sus condiciones económicas e incluso, de movilidad social. Aun cuando argumentaban tener muy pocos recursos para el mantenimiento de la familia, todos ellos tenían el deseo de que sus vástagos continuaran con sus estudios, por lo cual, preferían mantener a los jóvenes en la escuela secundaria que enviarlos a trabajar.

Por otra parte, cabe resaltar el empeño de los padres y las madres por demostrar que eran dignos de ser favorecidos con la exención del pago, para lo cual, recurrieron a un tercero que confirmara su modo honesto de vivir, y quizá algo más: el hecho de que reunían condiciones para obtener buen provecho del beneficio recibido. Es importante señalar que la SEP no establecía como requisito el envío de cartas de recomendación de terceros para exceptuar del pago de las cuotas requeridas al alumno y, sin embargo, esto ocurría con frecuencia. Si durante el siglo xix los pobres merecedores fueron juzgados por su moralidad, y el "modo honesto de vivir" fue requisito constitucional para la ciudadanía, tras la revolución el requisito de la honradez siguió apareciendo en el caso de las cuotas y becas de las secundarias, aunque, como veremos más adelante, también aparecieron nuevos discursos sobre el derecho a la educación.

En 1936, en el marco de la educación socialista, el discurso oficial respecto a la democratización de la enseñanza secundaria se volvió más radical. Por un lado, la SEP reportó que en 1935 dos terceras partes de los alumnos inscritos en secundaria habían sido exceptuados del pago de colegiatura, por lo cual, la recaudación del erario por este concepto era muy escasa; además de que la existencia de dicho pago, aunque no todos los estudiantes lo cubrían, disminuía el carácter popular que el nivel educativo debía tener. Por el otro, en un giro de $180^{\circ}$ en el discurso, frente a lo que había manejado en años anteriores, la SEP indicó que, de acuerdo con sus estadísticas, 76.7\% de los alumnos

\section{(이(1) $(2$}


inscritos en 1935 pertenecían a la clase trabajadora, $19.86 \%$ a la clase media y $3.44 \%$ a la acomodada, por lo cual, era menester que se decretara la gratuidad de la educación secundaria para que esa masa proletaria tuviera verdadero acceso a este nivel educativo. Me resulta importante resaltar que el número de alumnos becados en las secundarias federales se incrementó de manera extraordinaria, de un promedio de $11.73 \%$ por secundaria en 1933, a más de $50 \%$ en 1936. Estas cifras pueden representar el interés que tenían los padres de familia por mantener a sus hijos en las secundarias, aun cuando no tuvieran los recursos suficientes para pagar las cuotas de inscripción y colegiatura, lo cual nos habla de una gran demanda de este tipo de educación entre las familias de las clases bajas y de una clase media precaria o empobrecida.

Por otro lado, es interesante ver cómo el discurso oficial buscó, a partir de las cifras referidas, ser más congruente en el sentido de que se otorgaba la gratuidad de la secundaria para el beneficio de las clases trabajadoras y no de las clases medias -que era el sector que, según los informes de la SEP en los años anteriores, ocupaba la mayoría de las aulas de las secundarias federales-. Por supuesto que el repentino cambio en las cifras de clase "trabajadora" y clase "media" sugiere que la transformación no se debió tanto a un cambio representativo y rápido en la composición del alumnado, sino al cambio de los criterios de la SEP para contabilizar a miembros de distintas clases sociales. El último argumento de la sEP para establecer la gratuidad de la enseñanza secundaria fue que, si era la intención del ejecutivo federal establecer la gratuidad de la educación superior, con mayor razón tendría que serlo la secundaria. De esta forma, en 1936 se decretó la gratuidad de la educación secundaria, derogando los cobros de colegiatura que se venían haciendo en años anteriores (Memoria, 1936 p. 92). Con ello, el argumento de la calidad moral del pobre merecedor dejó de ser necesario y el costo familiar de enviar a los hijos a la secundaria disminuyó.

\section{LA DEMANDA SOCIAL DE EDUCACIÓN SECUNDARIA Y LA DEBILIDAD DEL ESTADO PARA SATISFACERLA: ESPACIO DE NEGOCIACIÓN PARA LOS CIUDADANOS}

Para 1934 existían en el Distrito Federal diez secundarias federales, incluidas dos nocturnas, la número 5 para varones y la 9 para mujeres. A excepción de los planteles número 8 y 10, establecidos en San Pedro de los Pinos y Mix-

\section{(이요 $\$$}


coac, respectivamente, la mayoría de estas escuelas se ubicaba en el centro de la ciudad o hacia la zona norte del Zócalo capitalino. ${ }^{22}$ Para entonces, en el centro existían algunos asentamientos, como las vecindades, habitadas por los sectores populares, además de que, pasado el movimiento revolucionario, muchas de las familias acomodadas y de clase media habían salido de esta zona para asentarse en colonias como la Juárez, la Roma, la Del Valle y las Lomas de Chapultepec (Miranda, 2008), por lo que podríamos pensar que la ubicación de las primeras escuelas secundarias buscaba atender a la población menos favorecida.

Este fue uno de los argumentos de los funcionarios de la SEP para crear el nivel secundario: que los hijos de las familias trabajadoras, sobre todo las urbanas, tuvieran acceso a la educación posprimaria. Para los años veinte, la Escuela Nacional Preparatoria (ENP) ofertaba este tipo de cursos ligados a los estudios superiores, sin embargo, eran pocos los jóvenes que tenían acceso a ellos. Las cifras mencionadas al inicio de este trabajo indican que el interés por la educación secundaria por parte de las familias del Distrito Federal fue alto. Sin embargo, no todos los padres que enviaron a sus hijos a las secundarias federales pertenecían a esa clase trabajadora que la SEP argumentaba sería beneficiaria directa del nuevo nivel educativo.

De acuerdo con los propios datos de la SEP, que contradecían el discurso gubernamental a favor de las clases trabajadoras, para los años treinta del siglo xx acudían a las escuelas secundarias federales jóvenes procedentes en su mayoría de los sectores medios, aunque también había estudiantes de las clases menos favorecidas, e incluso de algunas familias acomodadas. Para esta época la SEP no contaba con los recursos monetarios y de infraestructura suficientes para soportar dicho sistema educativo. Un ejemplo de ello fue la insuficiencia de edificios para abrir nuevos centros escolares que albergaran a los estudiantes de secundaria en el Distrito Federal. ${ }^{23}$

Por su parte, para los padres de familia era importante que sus hijos pudieran acudir a una escuela cercana a su domicilio, con lo cual se evitarían

${ }^{22}$ Fondo Departamento de Enseñanza Secundaria en el Distrito Federal. Escuelas Secundarias Federales. 1931-1944. Caja 2, leg. 2. Ahsep, México.

${ }^{23}$ Una de las estrategias del gobierno federal para abrir nuevas secundarias federales fue la expropiación de bienes clericales. En 1933, la SEP tomó posesión del edificio del Buen Pastor, localizado entre la Calle 4 y Avenida $1^{\circ}$ de Mayo, en San Pedro de los Pinos, para trasladar ahí la Secundaria número 8 (Memoria, 1933, pp. 199 y 200). En febrero de 1934, la SEP instaló en el edificio expropiado al Colegio Teresiano, ubicado en la calle de Goya número 34, en Mixcoac, la Secundaria 10 (Castillo, 2004, pp. 42-48).

\section{(ㅇ)(1) $\$$}


los riesgos de utilizar el transporte público, además de que ahorrarían en tiempo y dinero de transportación. Así lo estableció el Comité Pro-Escuela Secundaria de Coyoacán, una organización de padres de familia que exigió al jefe del Departamento de Escuelas Secundarias de la SEP, en 1932, la instalación de una secundaria para los hijos de los vecinos de Coyoacán, Xochimilco, Tlalpan, Churubusco, General Anaya, Los Reyes, San Francisco y Villa Obregón. El Comité apeló al discurso democratizador de la SEP; argumentó que, de abrirse un centro escolar de este tipo se produciría un "aumento del censo escolar para estudios secundarios, porque el ahorro del tiempo y de dinero que tendrían los padres [al enviar a sus hijos a una escuela cercana a sus domicilios] serían más de un sesenta por ciento". Otros argumentos del Comité para que se abriera una secundaria en Coyoacán giraron en torno a la vigilancia y disciplina de sus hijos, pues consideraban que el centro del Distrito Federal albergaba espacios "de distracción y de vicio" donde los jóvenes desperdiciaban su tiempo; además de "los peligros a que frecuentemente se ven expuestos los niños con el tránsito de vehículos [...]; las penas y amarguras de los padres cuando sus hijos no regresan oportunamente a sus casas, $y$ la tardanza con que se les administran sus alimentos por el mucho tiempo que emplean en los tranvías y camiones". ${ }^{24}$

Pareciera que los habitantes de Coyoacán, San Ángel, San Pedro de los Pinos y Mixcoac sentían una gran distancia, no sólo física, sino también de estilos de vida, respecto a los del centro capitalino, zona que identificaban como empobrecida y, por lo tanto, peligrosa, por lo cual requerían que sus hijos se mantuvieran alejados de ella. En cuanto a "los centros de distracción y de vicio" referidos por los padres de familia del Comité Pro-Escuela Secundaria de Coyocacán, el centro del Distrito Federal ofrecía una gama de diversiones que a los ojos de los guardianes de las buenas costumbres podían corromper a los jóvenes, tales como los salones de baile, las peleas de box, el circo, las carpas y los cines (Sosenski, 2006). Todas estas imágenes citadinas configuraron las representaciones sociales $-\mathrm{y}$ de moralidad- de los peligros a los que se exponían los niños y jóvenes estudiantes, en especial las mujeres, pues en el traslado diario a sus planteles escolares presenciaban innumerables escenas de "malos ejemplos" que corrompían sus frágiles conciencias. De

${ }^{24}$ Memorándum dirigido al jefe del Departamento de Escuelas Secundarias de la SEP. 30 de diciembre de 1932. Fondo Departamento de Enseñanza Secundaria en el Distrito Federal. Escuelas Particulares Incorporadas. 1927-1935. Escuela Secundaria Lauro Aguirre, Coyoacán, D. F. Caja 3, exp. 3. Ahsep, México.

\section{()(1) $(9$}


ahí la necesidad de los padres de familia de solicitar a la Secretaría de Educación el establecimiento de secundarias federales cercanas a sus domicilios.

Un caso muestra las dificultades que tenía la SEP con el asunto de las instalaciones y cómo esta situación detonó las demandas de los padres de familia: en la esquina formada por las calles de Artes y Miguel E. Schultz, cerca de la colonia San Rafael, al norponiente del Zócalo capitalino, se encontraba localizada la Secundaria Federal número 6, exclusiva para señoritas. En enero de 1932, este centro escolar se vio inmerso en una polémica entre los padres de familia y la SEP, pues la Secretaría había ordenado su traslado a Parque Lira -en Tacubaya-dado que la Fundación Dondé, dueña del edificio que albergaba a la Secundaria, no quería disminuir el cobro de la renta mensual -de 1395 pesos-, y la SEP no contaba con el presupuesto suficiente para cubrir más dicho gasto. ${ }^{25}$ Ante esta medida, los padres y madres de familia, junto con la directora del plantel, se organizaron y llevaron a cabo una reunión donde, según una nota periodística del 6 de enero de 1932:

Apenas comenzada la junta, los padres de familia se dividieron en dos bandos: unos que desean que la Secundaria en mención, sea trasladada a Tacubaya y otros, que siga donde está. No se pusieron de acuerdo y entonces una comisión numerosa de ellos, formada por padres de San Ángel, Mixcoac y Tacubaya, se dirigió en busca del Secretario [de Educación] Bassols para exponerle sus puntos de vista, que son los que siguen: primero, que como este año se va a trabajar las mañanas y las tardes, esta disposición demandará dobles gastos para los padres que radican en dichas municipalidades; que es muy reducido el tiempo que emplearían para comer y regresar a la calle de las Artes, donde está la escuela mencionada; que Tacubaya es un lugar de importancia indudable, en nuestra metrópoli, tanto que reclama una escuela secundaria, además de que en ella están varios institutos científicos, como el Observatorio Astronómico, el de Estudios Geográficos y Climatológicos y algunas fábricas, lo cual contribuirá a dar a dicha escuela muy buenas posibilidades y medios de cultura; [...] Agregan los peticionarios que de instalarse la escuela en el Parque Lira, quedará en un paraje equidistante de México y San Ángel. ${ }^{26}$

${ }^{25}$ Una vez más surge el problema por falta de escuelas secundarias. A pesar de que este año se cobrarán diez pesos por inscripción no son suficientes los planteles que existen. Excélsior, 6 de enero de 1932, primera plana.

${ }^{26}$ Una vez más surge el problema por falta de escuelas secundarias. A pesar de que este año se cobrarán diez pesos por inscripción no son suficientes los planteles que existen. Excélsior, 6 de enero de 1932, primera plana.

\section{(ㅇ)(1) $\$$}


Por su parte, la Fundación Dondé, al ver que perdería la renta del edifício con el cambio de domicilio, acordó con la SEP disminuir el cobro a 800 pesos mensuales, de los cuales la Secretaría sólo pagaría 600 y los 200 pesos restantes correrían a cargo de los padres de familia. ${ }^{27}$ Así, dada la insuficiencia presupuestal de la SEP, los padres que no querían que se cambiara la ubicación de la Secundaria número 6 lograron su objetivo, ya que tuvieron la oportunidad de negociar con las autoridades educativas y ambos aceptaron compartir la responsabilidad del pago de la renta de las instalaciones.

Sin embargo, destaca en los argumentos de los padres y las madres de familia la importancia de la noción de ahorro del tiempo de traslado de las alumnas de la zona de Tacubaya al centro de la ciudad, así como del gasto de transportación y comidas que implicaba el horario escolar dividido en mañana y tarde. La distancia no era la única preocupación de quienes pedían un centro escolar cercano a sus domicilios, su argumento también se basaba en el reconocimiento de Tacubaya como una zona próspera de la metrópoli, por lo cual ameritaba contar con su propia secundaria federal. Estas retóricas pueden ser vistas como parte de los imaginarios que compartieron las incipientes clases medias que habitaron en la época la parte surponiente del Distrito Federal (Miranda, 2007), lo cual dio sentido a una experiencia de clase que los distinguió de otros sectores sociales de la ciudad.

Por otro lado, la Secundaria Federal número 8 fue creada en 1930 como parte de una medida de la SEP para disminuir la matrícula de la Secundaria número 2, la cual no contaba con las instalaciones suficientes para albergar a los 1418 alumnos inscritos. ${ }^{28}$ El 22 de abril de ese año, la Secretaría de Educación separó un contingente de 500 alumnas de la Secundaria número 2 y creó la número 8 especial para señoritas; ambas compartían el mismo edificio en la colonia San Rafael, pero en distintos horarios (Memoria, 1930, p. 357). En 1933, la Sep trasladó a la Calle 4 y Avenida $1^{\circ}$ de Mayo, en San Pedro de los Pinos, la Secundaria número 8; debido, tal vez, a las presiones de los padres de la Secundaria número 6, que demandaban una nueva escuela para señoritas en Tacubaya, zona aledaña a San Pedro de los Pinos. Las nuevas y amplias instalaciones permitieron a la directora de la Secundaria número 8, Soledad Anaya Solórzano, crear un servicio de comedor, grandes laborato-

${ }^{27}$ Una vez más surge el problema por falta de escuelas secundarias. A pesar de que este año se cobrarán diez pesos por inscripción no son suficientes los planteles que existen. Excélsior, 6 de enero de 1932, primera plana.

${ }^{28}$ En ese mismo año dejaría de funcionar como anexa a la Normal de Maestros y se constituiría como secundaria federal (Memoria, 1930, p. 357).

\section{(ㅇ)(1) $\$$}


rios y salones de talleres para el uso de alumnas y profesores (Memoria, 1933, pp. 199 y 200).

Dada la amplitud del edificio de la Secundaria número 8, en enero de 1937 la casa de Maternidad $1^{\circ}$ de Mayo solicitó al secretario de Educación que se le donara un ala de las instalaciones para ubicar ahí a una parte de su población. Ante el riesgo de perder algunos salones y el comedor, los padres y madres de familia de la Secundaria número 8 organizaron una comisión integrada por Consuelo N. de Bernal, Sofía C. de González, Angelina H. de Casas Alatriste y Jesús Rico, que visitó al presidente de la república, Lázaro Cárdenas, y le pidió que no se llevara a cabo tal mutilación; su petición fue remitida al secretario de Educación, Gonzalo Vázquez Vela, quien les prometió resolver con justicia el caso. ${ }^{29}$

Al no recibir pronta respuesta, la comisión de padres y madres envió una carta a Vázquez Vela fechada el 2 de enero de 1937, donde reconocían la importancia de la instalación de una Casa de Maternidad, pero establecían que la educación tenía mayor utilidad social que la beneficencia, además de que el impacto de la disminución de instalaciones en la educación de sus hijos sería muy grande, ya que se encontraban en "la edad más difícil", lo que hacía necesario que se les tuviera "mayores atenciones". Otro argumento en contra de la división del edificio iba en el sentido de que "en caso de que se trate de un simple fraccionamiento, nos permitimos recordarle que la higiene prohíbe que sean adyacentes hospitales y escuelas". Por último, los padres le hacían ver en su carta al secretario de Educación que esta dependencia no tenía por qué hacerse cargo de los asuntos de la beneficencia social, y mucho menos tenía por qué verse perjudicado el campo educativo en beneficio de otros sectores sociales. ${ }^{30}$

La exigencia de los padres y las madres de la Secundaria número 8 tuvo eco en las autoridades, no sólo las educativas, también en la instancia superior del Estado, pues el 23 de enero de 1937 recibieron un telegrama del jefe del Departamento de Enseñanza Secundaria, quien les comunicó que, por acuerdo del presidente de la república, no sería mutilado el edificio escolar. A la luz del análisis de las prácticas ciudadanas, la polémica por el edificio de la Secundaria número 8 se convierte en un ejemplo de cómo los padres de familia articula-

${ }^{29}$ Fondo Departamento de Enseñanza Secundaria en el Distrito Federal. Escuela Federal No. 8. 1935-1937. Caja 12, leg. 21, fs. 1-6. AHSEp, México.

${ }^{30}$ Fondo Departamento de Enseñanza Secundaria en el Distrito Federal. Escuela Federal No. 8. 1935-1937. Caja 12, leg. 21, fs. 1-6. AHSEP, México.

\section{(ㄷ)(1) $(3$}


ron un discurso donde demostraron conocer los reglamentos y parámetros higienistas de la época, es decir, contaban con un bagaje de información que les permitió abrir un espacio de negociación con la máxima autoridad educativa y el presidente de la república. Con ello, la defensa del derecho a la educación secundaria de los hijos se articuló con la exigencia de contar con un edificio que reuniera las condiciones materiales adecuadas para los adolescentes.

La organización de una comisión para representar a los padres de familia -la cual en su mayoría estuvo integrada por mujeres-, y que tuvo acceso a la oficina presidencial, y el envío constante de correspondencia al secretario de Educación para exigir una respuesta favorable, constituyeron una gama de tácticas surgidas de la vida cotidiana (Certeau, 1996) por medio de las cuales los padres y las madres de familia protagonistas de este episodio histórico construyeron una arena política donde pudieron colocar como tema de negociación su preocupación e interés por el bienestar de sus hijos en las secundarias federales. Además, aun cuando fuera sólo como portavoces, pues tal vez los padres no tenían el tiempo para asistir a las citas por no faltar a sus trabajos, las madres de familia tuvieron una participación activa en las entrevistas con las autoridades, lo cual las colocó en un espacio que se podría pensar sólo para el ejercicio masculino, pero al cual, cumpliendo con su papel de encargadas de la educación de sus hijos, lograron acceder.

\section{EDUCACIÓN SECUNDARIA PARA LOS HIJOS: ENTRE LA SÚPLICA MORAL Y LA DEMANDA DE DERECHO CIUDADANO}

Las formas de solicitar a las autoridades educativas la exención del pago de cuotas por parte de los padres de familia me lleva a plantear la siguiente pregunta: ¿los padres y madres de familia percibían la educación de sus hijos como un beneficio que el Estado daba a los sujetos merecedores o como un derecho ciudadano universal, el cual debía ser satisfecho por el gobierno federal? Aboites (2012, p. 367) establece que los movimientos sociales de finales del siglo xix e inicios del xx que dieron como resultado la conformación de los Estados modernos, impusieron la necesidad de establecer acuerdos sociales amplios, donde los derechos sociales para las mayorías incluidos en las constituciones nacionales sirvieron como instrumentos de legitimación y consenso. Para el caso de México, continúa el autor, el derecho a la tierra, los derechos laborales, el derecho a la educación, a la seguridad social y a la

\section{(ㅇ)(1) $(3$}


vivienda, fueron elementos sustanciales para ofrecer una relativa estabilidad social, a manera de un acuerdo entre el Estado y la sociedad.

Los casos de los padres y madres que solicitaron la exención de los pagos de colegiatura para que sus hijos continuaran en las secundarias, basados en argumentos que denotaban su condición de clase trabajadora y, en el caso de las madres, de género, erigieron una figura del Estado como el benefactor de la población, el que los ayudaría a mejorar sus condiciones sociales a través de las becas otorgadas a sus hijos y el que, en última instancia, podía decidir, a través de este beneficio educativo, quién tenía acceso a la educación secundaria. Pero sobre todo, hicieron necesario el cumplimiento de requisitos especiales, en este caso el de ser honrados y honorables y, por lo tanto, merecedores. Sin embargo, no todos los padres de familia tuvieron esta visión sobre el pacto Estado-ciudadanos; algunos de ellos destacaron la obligación del gobierno federal de proporcionar educación secundaria para sus hijos bajo el argumento del derecho que la revolución les había heredado.

Este fue el caso del señor Manuel D. García, padre de la niña Trinidad García Alanís y mecánico de profesión, quien, el 11 de enero de 1935, envió una carta al secretario de Educación, Ignacio García Téllez, para solicitarle una explicación porque la directora de la Secundaria número 8, la profesora Soledad Anaya Solórzano, le había negado la inscripción de su hija al tercer año debido a que había reprobado dos materias. El señor García expresaba que:

Como padre y obrero que soy, procuro por la educación de mis hijos; por el Progreso, la Libertad, la Igualdad y Fraternidad de todos los hombres hasta donde mi progreso y fuerzas alcanzan. Estando por lo tanto, en todo de acuerdo con los Ideales de la Revolución, que nuestro Gobierno con mucho afán desea realizar; estando así mismo, de acuerdo con la implantación de "La Escuela Socialista"; porque comprendo, que esa es la única manera de acabar con las religiones que siempre han sido la rémora de los pueblos. [...]

Pregunto, Señor Secretario: ¿Cómo es esto?... Que a nosotros, los trabajadores, que de buena voluntad colaboramos sinceramente con el Gobierno ise nos pongan estos obstáculos? Siendo, como en efecto es, que el propio Gobierno ha hecho extensiva la invitación a los fanáticos para que manden a sus hijos a la Escuela. Pregunto: ¿cómo es esto? ${ }^{31}$

${ }^{31}$ Manuel D. García. Carta al secretario de Educación Pública. 11 de enero de 1935. Fondo Departamento de Enseñanza Secundaria en el Distrito Federal. 1931-1944. Escuela Secundaria No. 8. Caja 2, leg. 35. Ahsep, México. Las cursivas son mías.

\section{(ㅇ)(1) $\$$}


Aun cuando el señor García no tenía acreditados estudios superiores y se desempeñaba como "maestro mecánico" de la Casa Buick, parecía tener muy claro el pacto gobierno-ciudadano del Estado posrevolucionario, es decir, defendía la idea de que debía existir una reciprocidad entre el Estado y el pueblo: si el ciudadano cumplía, el gobierno también. En su carta, el padre de la alumna Trinidad argumentaba que estaba de acuerdo con la labor educativa del Estado. Además, no se manifestaba sólo a título personal, también se posicionaba como parte de esa clase obrera a la cual el gobierno cardenista buscaba beneficiar con sus políticas educativas, por ello, si él respaldaba los "ideales de la revolución", específicamente los que tenían que ver con el progreso de la nación, se preguntaba por qué el gobierno, a partir de las decisiones tomadas por la profesora Anaya, no cumplía con la obligación de proporcionar educación a su hija.

Por su parte, la directora de la Secundaria número 8 había tomado la decisión de no inscribir a Trinidad al siguiente año escolar debido a que la alumna había reprobado dos materias, con lo cual, de acuerdo con el reglamento de la secundaria, no podía avanzar al siguiente grado, sino que debía repetir el mismo año. Para el señor García el hecho de que su hija se retrasara un año no era la mejor opción, de ahí que buscara el apoyo de la autoridad superior para que su hija pudiera ser inscrita al tercer año de secundaria. Finalmente, el padre de Trinidad logró su cometido, pues la carta incluía una nota escrita a mano y con lápiz que decía: "Ya está inscrita" ${ }^{32}$ Así pues, el señor García no quería tan sólo que su hija tuviera un lugar en la escuela, como de hecho lo tendría si repetía el $2^{\circ}$ año, sino que buscó ampliar la idea de derecho de educación para que incluyera también un derecho a no someterse a la evaluación de conocimientos por parte de la escuela si esta le resultaba adversa a su hija.

A finales de agosto de 1935, el licenciado Enrique Escalante Novelo, abogado de profesión, le envió una carta al profesor Juan B. Salazar, jefe del Departamento de Enseñanza Secundaria, para expresarle su inconformidad ante la resolución de la directora de la Secundaria número 8 de crear un grupo "Preparativo" con 35 alumnas de primer grado, entre ellas su hija, Alicia Escalante Sosa. En dicho grupo, según la directora, las alumnas recibirían las clases que las prepararían mejor para volver a cursar el primer año. Cabe

${ }^{32}$ Manuel D. García. Carta al secretario de Educación Pública. 11 de enero de 1935. Fondo Departamento de Enseñanza Secundaria en el Distrito Federal. 1931-1944. Escuela Secundaria No. 8. Caja 2, leg. 35. Ahsep, México.

\section{(이요 $\$$}


aclarar que la intención de la profesora Anaya era separar a estas alumnas del resto aunque todavía no terminaba el año escolar, por lo tanto, el padre de Alicia no estuvo de acuerdo con que se interrumpiera la educación de su hija y, mucho menos, que con ello su hija cayera en retraso escolar -lo cual le podía significar cierto estigma social-. Ante esta medida, el licenciado Escalante se entrevistó con la profesora Anaya para pedirle que su hija no fuera incluida en dicho grupo especial, pero la profesora le contestó que era lo mejor para la alumna, pues le sería imposible aprobar todas sus materias y así poder ingresar al siguiente año. Debido al rechazo de la directora, el señor Escalante acudió a la autoridad del jefe del Departamento de Enseñanza Secundaria para que solucionara a su favor el conflicto. Así lo establecía en su carta:

Con la formación del grupo especial ideado por la mencionada señorita Directora, ya que el reglamento para Escuelas Secundarias no faculta la formación de esos grupos especiales, repito, como esto perjudica a mi referida hija, porque la priva de la oportunidad de educarse, y de ejercitar los derechos que le concede el mencionado reglamento, ocurro a Usted muy atentamente, suplicándole sea bien servido en disponer que mi referida hija continúe su curso en forma normal tal como lo dispone el referido reglamento. ${ }^{33}$

Por su parte, la directora defendió su posición ante el jefe del Departamento de Enseñanza Secundaria a través de un minucioso informe donde detallaba su encuentro con el padre de Alicia Escalante y recalcaba el beneficio educativo que traería a las alumnas el permanecer en el grupo especial, pues en él se atenderían los problemas que presentaban dichas estudiantes en las áreas de lenguaje, cálculo aritmético elemental, civismo y actividades sociales, biblioteca, cocina y música.

Dado que el conflicto no pudo ser solucionado -aun cuando el licenciado Escalante decía haber obtenido la autorización del jefe del DEs para que su hija continuara sus estudios en el grupo regular-, el padre de la estudiante pidió a la directora de la Secundaria número 8 que diera de baja a su hija y que le regresara su certificado de primaria para poder inscribirla en la Secundaria número 6 el siguiente año. En una carta final, el padre de Alicia

33 Enrique Escalante Novelo. Carta a Juan B. Salazar. 30 de agosto de 1935. Fondo Departamento de Enseñanza Secundaria en el Distrito Federal. 1931-1944. Escuela Secundaria No. 8. Caja 2, leg. 33. Ahsep, México. Las cursivas son mías.

\section{(ㄷ)(1) $(3$}


le exponía a la profesora Anaya su molestia, dado que, según él, se le había quitado a su hija el derecho que la ley le otorgaba para cursar los estudios secundarios:

Entendía yo que para pasar el primer año, bastaba cubrir las cuotas de colegiatura, cooperativa y demás gastos, asistir con puntualidad y estudiar las tareas escolares. Ignoraba que se tenía que cursar un grupo preparatorio. [...] Si mi hija resultara reprobada al fin del curso, bien, pero ¿por qué meses antes de terminar el curso se le prohíbe de la oportunidad de estudiar y de un tajo se le quitan los derechos que la ley le concede, como el de presentar exámenes extraordinarios, llegado el caso? Bien que ella y muchas más sean reprobadas, pero que sea en buena lid y no se les perjudique con la formación de grupos preparatorios inventados por Ud. violando la Ley y a su capricho ya formó un nuevo grupo, ya suprime el Grupo "B" del primer año, tal parece que no es una escuela sujeta a leyes reglamentarias, sino algo de la propiedad de Ud. en donde hace y deshace a gusto y voluntad suya. [...] A semejanza de una adivina Ud. predijo el futuro de esas educandas, pues meses antes de que terminen su curso, adivinó Ud. que iban a ser reprobadas e inventó Ud. la creación del grupo preparatorio y las incorporó a él. ${ }^{34}$

El padre de Alicia Escalante, abogado de clase media urbana, utilizó un discurso basado en la idea del derecho a la educación; trató de solucionar el conflicto con la directora de la Secundaria número 8 , pero ante la negación de ella, acudió a su jefe próximo y, nuevamente, bajo el argumento de que la profesora Anaya incumplía la ley al negarle a su hija continuar con sus estudios en el grupo regular, buscó una respuesta a su petición. Llama la atención cómo, en su carta dirigida a la profesora, el licenciado Escalante recurrió a la idea de que si había cumplido con el pago de las cuotas de colegiatura requeridas según el reglamento de la SEP, tenía el derecho a exigir la educación de su hija. A diferencia del caso del maestro mecánico García, el licenciado Escalante no se sintió con la necesidad de alegar su apoyo a los "ideales de la revolución" ni a la política educativa socialista. Sin embargo, cabe resaltar que pese a que el padre de Alicia decidió darla de baja de la Secundaria número 8, su queja no se extendía al sistema escolar oficial, pues decidió inscribirla en la número 6.

${ }^{34}$ Enrique Escalante Novelo. Carta a directora de Escuela Secundaria No. 8. Septiembre de 1935. Fondo Departamento de Enseñanza Secundaria en el Distrito Federal. 1931-1944. Escuela Secundaria No. 8. Caja 2, leg. 33. A HSEP, México. Las cursivas son mías.

\section{(ㅇ)(1) 3}


Tenemos entonces un caso donde los argumentos del padre de familia refuerzan la idea de un derecho ciudadano independiente de la lealtad a un particular gobierno revolucionario o a determinada política socialista. Mientras que en el caso del señor García, la lealtad al gobierno si no un prerrequisito forzoso, sí era al menos parte de la argumentación para exigir un derecho.

A pesar de las diferencias entre los casos del padre de Trinidad García Alanís y el de Alicia Escalante Sosa, vemos cómo estos padres de la Secundaria número 8 articularon sus demandas con un discurso informado acerca del derecho a la educación de sus hijas -en el sentido de una demanda ciudadana, al igual que los padres de la Secundaria número 8 que argumentaron la defensa de las instalaciones con información relativa los reglamentos higienistas-, y no como una petición de una dádiva o un favor, como lo hicieron otros padres y madres de familia en el caso de la solicitud de exención de cuotas. También resalta el hecho de que ambos eran varones y que en ninguna de las cartas se hace alusión a la intervención de las madres, ni como intermediarias entre la directora y el padre de familia. Por último, en ambos casos, la profesora Soledad Anaya Solórzano se vio inmersa en una situación donde, al tomar medidas que según su punto de vista redituaban en el mejor aprovechamiento de las alumnas, trastocó los intereses de los padres de las mismas, lo cual le valió la intervención de la autoridad superior y, en el caso de Trinidad García, tuvo que revertir su resolución. En este sentido, los señores García y Escalante pusieron en tela de juicio la capacidad de la directora Anaya para tomar decisiones importantes sobre la educación de sus hijas, lo cual nos muestra que para estos padres la autoridad educativa y, en última instancia, estatal, también podía ser cuestionada. Aunado a ello, la preocupación de ambos padres por que sus hijas no se retrasaran con respecto a sus compañeras adquiere sentido si lo analizamos, siguiendo a Loaeza (1999), como parte de los intereses de clase de los sectores medios urbanos y de quienes aspiraban a acceder a dicho sector: buscaban ascender en la escala del prestigio social a partir de la obtención de un nivel superior de estudios que el de la población promedio.

\section{COMENTARIOS FINALES}

El nivel secundario fue creado bajo un discurso de legitimación de los gobiernos posrevolucionarios en el sentido de democratizar la educación posprimaria y establecer escuelas a las que tuvieran acceso las clases populares

\section{(ㅇ)(1) $(3$}


urbanas, además de la intención implícita de quitar el control de estos estudios a la Universidad Nacional. Por otra parte, la constitución de las escuelas secundarias estuvo marcada también por los intereses de los padres de familia, quienes la vislumbraron como un medio de movilidad social o como instrumento de distinción de la clase media urbana -en el sentido de alcanzar un nivel educativo superior-, y exigieron nuevos planteles, defendieron los existentes $y$, en última instancia, abonaron a la discusión de la pertinencia de decretar su gratuidad.

Como hemos visto en los casos analizados, las formas de dirigirse a la autoridad educativa muestran la conformación de un ejemplo de una cultura política de la sociedad urbana en el México posrevolucionario en el que observamos un continuum que iba desde la súplica, la reverencia a la autoridad y el reconocimiento social del honor -a la manera de un pobre merecedor o de un ciudadano que forzosamente debía mostrar su honestidad-, hasta la exigencia de un derecho social bajo argumentos informados que reconocían el pacto Estado-ciudadano, con obligaciones del primero hacia el segundo.

Por último, cabe señalar que en las evidencias arriba analizadas no se manifiesta un cuestionamiento a la figura del monopolio educativo del Estado posrevolucionario. Los padres de familia se posicionaron ya fuera como suplicantes de un beneficio estatal o como ciudadanos que demandaban un derecho, con lo que establecieron negociaciones de acuerdo con sus preocupaciones en relación con la educación secundaria de sus hijos: crear más escuelas, ubicarlas cerca de sus domicilios, ser exentos de los pagos de cuotas y garantizar la permanencia de los hijos en las secundarias, así como evadir el estigma de alumno repetidor o retrasado.

Al comparar estas negociaciones tenemos que, en el contexto de fragilidad de las instituciones estatales, incluyendo la falta de recursos para sostener el nivel educativo secundario, los padres que acordaron pagar una parte de la renta del edificio escolar para que no cambiara su ubicación establecieron un tipo de ciudadanía donde el recurso económico los posicionó en un lugar más ventajoso frente a la autoridad. Por el contrario, los padres que argumentaron no tener dinero para pagar las cuotas exigidas por la SEP para que sus hijos estudiaran en las secundarias federales, se presentaron como pobres merecedores, además de que las madres tuvieron que apelar a la súplica, lo cual constriñó su forma de solicitar el beneficio de la política social de las becas. Con ello, vemos que las condiciones materiales y de género producían prácticas ciudadanas desiguales, con lo que la idea de que la ciudadanía homogeneiza a la población es puesta en entredicho en la realidad social, al

\section{(이요 $(3$}


mismo tiempo que la demanda educativa se fundamentaba en la creencia de que la escuela secundaria podía dar oportunidades a todos.

\section{LISTA DE REFERENCIAS}

Aboites, H. (2012). El derecho a la educación en México. Del liberalismo decimonónico al neoliberalismo del siglo xxi. Revista Mexicana de Investigación Educativa, 17(53), 361-389.

Aguirre, V., García I. y Valero A. (2002). De la caridad a la beneficencia pública en la ciudad de México. México: unam.

Alfonseca, J. (2005). El papel de las juntas y los comités de educación en la apropiación local de la escuela rural federal. Memoria, conocimiento y utopía. Anuario de la Sociedad Mexicana de Historia de la Educación, 1, 63-90.

Arredondo, M. A. (2007). Políticas públicas y educación secundaria en la primera mitad del siglo xix en México. Revista Mexicana de Investigación Educativa, 12(32), 37-62.

Arredondo, M. A. (2008). El proyecto educativo de la modernidad para los jóvenes. En M. A. Arredondo (aut. y comp.), Entre la primaria y la universidad, la educación de la juventud en la historia de México (pp. 63-76). México: Editorial Santillana/Universidad Pedagógica Nacional.

Arrom, S. M. (1988). Las mujeres de la ciudad de México 1790-1857. México: Siglo XXI.

Bertaccini, T. (2009). El régimen prísta frente a las clases medias 1943-1964. México: Conaculta.

Britton, J. A. (1976). Educación y radicalismo en México. II. Los años de Cárdenas (19341940). México: SEP.

Castillo, J. L. (2004). Entonces, Mixcoac... México: Consejo de la Crónica de la Ciudad de México.

Certeau, M. de (1996). La invención de lo cotidiano. I. Artes de hacer. México: Universidad Iberoamericana/Instituto Tecnológico y de Estudios Superiores de Occidente.

Civera, A. (1997). Entre surcos y letras. Educación para campesinos en los años treinta. México: El Colegio Mexiquense/IneHrm.

Civera, A. (2008). La secundaria como un proceso de construcción: un estudio de caso (1925-1980). En M. A. Arredondo (aut. y comp.), Entre la primaria y la universidad, la educación de la juventud en la historia de México (pp. 327-348). México: Editorial Santillana/Universidad Pedagógica Nacional.

Contreras E. (1978). Estratificación y movilidad social en la ciudad de México. México: UNAM.

\section{()(1) $\$$}


Gonzalbo, P. y Staples A. (coords.) (2012). Historia de la educación en la ciudad de México. México: Colmex.

González, M. (1974). Población y sociedad en México (1900-1970). México: unAM.

Guerra, F.-X. (2002). Súbditos o ciudadanos. En H. Sabato (coord.), Ciudadanía política y formación de las naciones. Perspectivas históricas de América Latina (pp. 33-61). México: Colmex.

Instituto Nacional de Estadística, Geografía e Informática (INEGI) (2000). Estadísticas Históricas de México (t. I). México: INEGI.

Iturriaga, J. E. (1987). La estructura social y cultural de México. México: SEP.

Loaeza, S. (1999). Clases medias y política en México. La querella escolar, 1959-1963. México: Colmex.

Lomnitz, C. (2000). La construcción de la ciudadanía en México. Metapolítica, 4(15), 128-149.

López, P. y Acevedo, A. (2012). Introducción. Los ciudadanos inesperados. En P. López y A. Acevedo (coords.), Ciudadanos inesperados: espacios de formación de la ciudadanía ayer y hoy (pp. 13-38). México: Colmex.

Lorenzo, M. D. (2011). El Estado como benefactor. Los pobres y la asistencia pública en la ciudad de México 1877-1905. México: Colmex/El Colegio Mexiquense.

Loyo, E. B. (2008). La escuela secundaria socialista en México. ¿Una opción de educación popular? (1925-1940). En M. A. Arredondo (aut. y comp.), Entre la primaria y la universidad, la educación de la juventud en la historia de México (pp. 271-292). México: Editorial Santillana/Universidad Pedagógica Nacional.

Mejía, R. (1976). Moisés Sáenz. Educador de México. Cincuentenario de la Fundación del Sistema Nacional de Escuelas Secundarias Mexicanas 1926-1976. México: Federación Editorial Mexicana.

Memoria que indica el estado que guarda el ramo de Educación Pública el 31 de agosto de 1930 (1930). México: Talleres Gráficos de la Nación.

Memoria relativa al estado que guarda el ramo de Educación Pública el 31 de agosto de 1932. T. I. Exposición (1932). México: Talleres Gráficos de la Nación.

Memoria relativa al estado que guarda el ramo de Educación Pública el 31 de agosto de 1933. T. I. Exposición (1933). México: Talleres Gráficos de la Nación.

Memoria de la Secretaría de Educación Pública. Septiembre de 1935-agosto de 1936 (1936). México: SEP.

Mentz, B. (2003). Introducción. En B. Mentz (coord.), Movilidad social de sectores medios en México. Una retrospectiva histórica (siglos XVII al Xx) (pp. 7-48). México: CIEsAs/Miguel Ángel Porrúa.

Miranda, S. (2007). Tacubaya de suburbio veraniego a ciudad. México: UNAM.

\section{()ㅜ(1) $(3$}


Miranda, S. (2008). La creación del Departamento del Distrito Federal. Urbanización, política y cambio institucional. México: UnAm.

Pérez, R. (1993). "Por la patria y por la raza", La derecha secular en el sexenio de Lázaro Cárdenas. México: UnAM.

Porter, S. (2002). Empleadas públicas: normas de feminidad, espacios burocráticos e identidad de la clase media en México durante la década de 1930. Signos Históricos, 11, 41-63.

Rockwell, E. (2007). Hacer escuela hacer estado. La educación posrevolucionaria vista desde Tlaxcala. México: Colmex/ciesas/Centro de Investigación y de Estudios Avanzados del Instituto Politécnico Nacional.

Rodríguez, A. (2010). Historia del desasosiego. La revolución en la ciudad de México, 19111922. México: Colmex.

Santos, A. (2000). La educación secundaria: perspectivas de su demanda. (Tesis de doctorado inédita). Universidad Autónoma de Aguascalientes, México.

Schell, P. A. (2003). Church and State Education in Revolutionary Mexico City. Arizona: The University of Arizona Press.

Sosenski, S. (2006). Diversiones malsanas: el cine y la infancia en la ciudad de México en la década de 1920. Secuencia, 66, 37-64.

Vaughan, M. K. (2000). La política cultural en la revolución. Maestros campesinos y escuelas en México 1930-190. México: SEP/FCE.

Vaughan, M. K. y Quintanilla, S. (1997). Presentación. En M. K. Vaughan y S. Quintanilla (coords.), Escuela y sociedad en el periodo cardenista (pp. 7-43). México: FCE.

\section{OTRAS FUENTES}

\section{Archivos}

AhSEP Archivo Histórico de la Secretaría de Educación Pública, México.

AHs10 Archivo Histórico de la Secundaria Federal No. 10 "Leopoldo Ayala”. México.

\section{Periódico}

Excélsior, México.

\section{()(1) $\circledast$}

